\title{
Choice of route for hysterectomy - evaluation of procedures performed in the gynaecological department of the Tuchola District Hospital, from 2005 to 2008
}

\author{
Krzysztof Klimczak ${ }^{1}$, Andrzej Malinowski², Cezary Dejewski ${ }^{3}$ \\ 1Department of Women's Diseases, St. Joseph's Hospital, Bremerhaven, Germany \\ 2Department of Operative and Endoscopic Gynaecology, Centrum Zdrowia Matki Polki Institute, Lodz, Poland \\ 3Department of Women's Diseases, St. Joseph's Hospital, Bremerhaven, Germany
}

Videosurgery and other miniinvasive techniques 2010; 5 (1): 14-18 DOI: 10.5114/wiitm.2010.13601

\begin{abstract}
Introduction: The latest trends in the field of hysterectomy have brought a marked reduction in the rate of open abdominal hysterectomy. The number of minimally invasive procedures - vaginal and laparoscopic hysterectomies has increased in many settings.

Aim: This study evaluates the route of all hysterectomies performed in the gynaecology department of the District Hospital in Tuchola, from 01.01.2005 to 31.12.2008. It is a follow-up study of the initial report published by the same authors in 2007, in 'Przegląd Menopauzalny'.

Material and methods: The authors analysed the percentage of hysterectomies performed via abdominal (AH), vaginal (VH) and laparoscopic access (LH) from 2005 to 2008, for benign diseases.

Results: A ten-fold decrease (from $81.35 \%$ in 2005 to $7.24 \%$ in 2007) in the rate of abdominal hysterectomy (AH) and three-fold increase in frequency of vaginal hysterectomy (VH), from 18.65\% in 2005 to $60.71 \%$ in 2006, were observed. Use of laparoscopic hysterectomy (LH) increased from 36.24\% in 2007 to $67.14 \%$ in 2008 - during 2 years from introduction of this procedure.

\section{Conclusions:}

1. A two-fold decrease in the first year, from 81.35 to $39.29 \%$, and ten-fold decrease in the next year, to $7.24 \%$, in the rate of abdominal hysterectomy $(\mathrm{AH})$ was observed.

2. Systematic physician training and proper patient qualification are followed by an increase in use of vaginal hysterectomy (VH) up to $60 \%$.

3. Conversion from laparoscopic hysterectomy to laparotomy and thermal injury to the ureter can occur in the beginning of the learning curve of $\mathrm{LH}$.
\end{abstract}

Key words: abdominal hysterectomy $(\mathrm{AH})$, vaginal hysterectomy $(\mathrm{VH})$, laparoscopic assisted vaginal hysterectomy (LAVH), laparoscopic total hysterectomy (LTH), laparoscopic supracervical hysterectomy (LASH). 


\section{Introduction}

Hysterectomy is one of the most common gynaecological procedures [1-4]. More than $90 \%$ of indications for hysterectomy are non-malignant diseases, i.e. myomas, intrauterine adenomatosis, abnormal bleeding from the uterus, pain localized to the lesser pelvis and posture abnormalities [5]. According to the route of access, abdominal hysterectomy $(\mathrm{AH})$, vaginal hysterectomy $(\mathrm{VH})$ or laparoscopic hysterectomy (LH) can be chosen. Vaginal hysterectomy can be performed as total or laparoscopically assisted vaginal hysterectomy (LAVH). Abdominal hysterectomy can be done as total or supracervical and laparoscopic one as laparoscopic total hysterectomy (LTH) or supracervical (LASH).

The benefits of vaginal and laparoscopic access in comparison to transabdominal are well known and accepted [6, 7]. Most centres worldwide aim to decrease the number of abdominal hysterectomies and increase the proportion of vaginal/laparoscopic procedures [8]. This originates from the desire for limited invasiveness of the procedure ('minimally invasive surgery', 'minimal access surgery'), shorter hospital stay, faster recovery time and superior cosmetic effect.

The majority of gynaecological units in Poland use the traditional transabdominal method of hysterectomy most frequently - per laparotomiam. Vaginal hysterectomy is performed relatively rarely (5-10\%), usually for disturbed statics of the reproductive organ (lowering/prolapse). Laparoscopic hysterectomy in Poland is performed even less often $[1,4]$.

\section{Aim}

The aim of the study was to analyse the access route for hysterectomy. The study was based on surgical procedures performed in the gynaecology unit of the Tuchola Hospital between January 1st 2005 and December $31^{\text {st }}$ 2008. This paper is a continuation of an article published by the same authors in 'Przeglad Menopauzalny' in 2007 as a preliminary report.

\section{Material and methods}

All physicians of the obstetrics/gynaecology department of the Tuchola Hospital have actively participated in an educational programme to improve qualifications in vaginal and laparoscopic procedures. The programme took the form of surgical workshops organized by the Department of Operative and Endoscopic Gynaecology of Centrum Zdrowia Matki Polki in Lodz, the Department of Women's Diseases of Ludvig Maximilian University in Munich - Amper Klinik Dachau, and workshops prepared locally in the Tuchola Hospital.

An analysis of the access for surgical resection of the uterus was performed on the material of the gynaecology unit of the Tuchola Hospital during 2005-2008. In 2006 the educational programme was initiated in our unit and the first LAVH was performed. The first LH was done in 2007.

\section{Results}

In 2005, 59 hysterectomies were performed, $81.35 \%$ (48) of which were transabdominal and $18.65 \%$ (11) vaginal procedures. Excision of the uterus via vaginal access was performed usually for disturbances in the statics of the reproductive organ.

In 2006, 84 hysterectomies were completed. Thirty-three of these (39.29\%) were abdominal and $60.71 \%$ (51) were vaginal procedures, including $5 \mathrm{LAVH}$. An increase of the rate of $\mathrm{VH}$ was a result of broadening the spectrum of indications for vaginal access (myomas without prolapse of the uterus) and of introducing laparoscopy-assisted vaginal hysterectomy.

In 2007, 69 hysterectomies were performed. Abdominal procedures accounted for only $7.24 \%$ $(n=5)$ and vaginal for $56.52 \%(n=39)$, including 13 LAVH. Totally LH was introduced and the percentage of these procedures was $36.24 \%(n=25)$, including 15 supracervical (LASH) and 10 total (LTH) excisions.

In 2008, 73 hysterectomies were done, with 7 (9.58\%) executed via abdominal access, 17 (23.28\%) vaginal, including $3 \mathrm{LAVH}$ and 49 (67.14\%) laparoscopic (48 LASH and 1 LTH procedure). These data are shown in Table I and Figures 1, 2.

During the study period, 5 conversions (6.8\%) from laparoscopic to abdominal procedures: 3 for intraoperative haemorrhage and 2 for significantly enlarged, myomatous uterus, weighing more than $1000 \mathrm{~g}$, with limited mobility were needed. One laparotomy was necessary after LAVH on the 14th post-operative day for abscess of the adnexa and one laparoscopic reoperation for haemorrhage from the cervical stump after LASH. The highest weight of the uterus excised via the vaginal route was $900 \mathrm{~g}$ and $760 \mathrm{~g}$ on laparoscopy. 
Table I. Rate of each hysterectomy type during 2005-2008

\begin{tabular}{|lcccc|}
\hline Year & Number of procedures & AH no. (\%) & VH no. (\%) & LH no. (\%) \\
\hline 2005 & 59 & $48(81.35)$ & $11(18.65)$ & \\
\hline 2006 & 84 & $33(39.29)$ & $51(60.71)$ & $25(36.24)$ \\
\hline 2007 & 69 & $5(7.24)$ & $39(56.52)$ & $49(67.14)$ \\
\hline 2008 & 73 & $7(9.58)$ & $17(23.28)$ & $74(26)$ \\
\hline Total & 285 & $93(32.6)$ & $118(41.4)$ & \\
\hline
\end{tabular}

$A H$-abdominal hysterectomy, $\mathrm{VH}$-vaginal hysterectomy, $\mathrm{LH}$ - laparoscopic hysterectomy

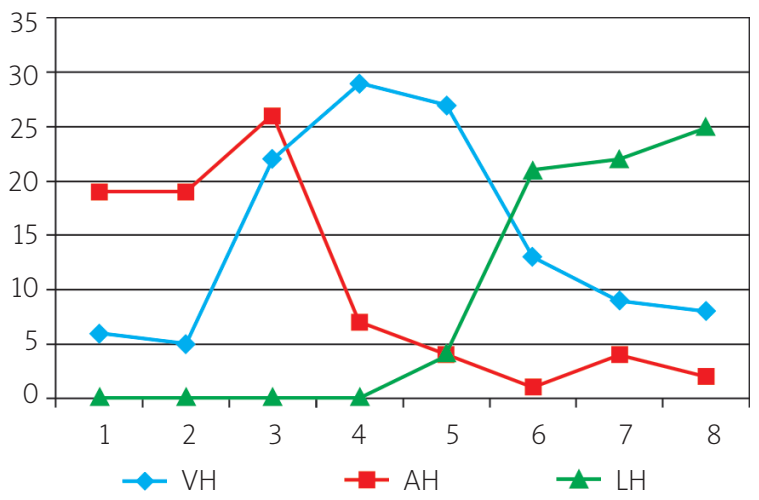

Figure 1. Number of hysterectomies performed in the department during 2005-2008 in 6-month intervals

During 2007-2008, 2 (2.8\%) major complications, i.e. injury to the ureter, occurred during laparoscopic hysterectomy (adnexal pathology and myomatous organ).

Patients with normal cervical cytology, who declared regular postoperative follow-up, were scheduled for LASH. Diagnosis of statics aberrances qualified patients to vaginal hysterectomy (VH or LAVH).

\section{Discussion}

In 2005 until mid 2006 vaginal hysterectomy was performed mainly (90\%) for prolapse/lowering of the reproductive organ. At the beginning of 2006 an educational programme was started and due to this programme 6 months later a three-fold increase in vaginal hysterectomies was observed with a consequent decrease in the number of abdominal excisions. Indications for transvaginal resection were broadened with myomas. This tendency was stable until mid

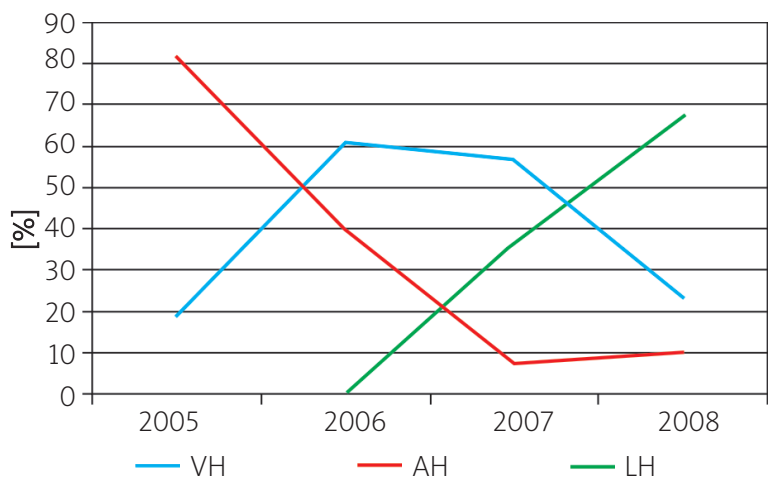

Figure 2. Learning curve as rates of different types of hysterectomies performed during 2005-2008

2007, when laparoscopic hysterectomy was implemented in the unit. Also, in 2006 laparoscopy-assisted vaginal hysterectomy was begun, which also influenced the rates of these procedures greatly.

In 2007, 69 hysterectomies were performed - a decrease in comparison to 2006 resulting from an increased number of laparoscopic myomectomies (8.62\% of all procedures). In March 2007, laparoscopic hysterectomies were started. The largest number of these procedures was done in September 2007 and April 2008 during surgical workshops organized at these times.

According to the literature, the vaginal hysterectomy rate should be anywhere between 70 and $80 \%$, and abdominal excision between 5 and 10\% [9, 10]. Laparoscopic hysterectomy is however still an infrequent procedure in Poland [4].

Implementation of the educational programme in 2006 and modification of qualification guidelines (expansion of indications) brought about an increase 
of the vaginal hysterectomy rate up to $60 \%$. As a result, the number of abdominal hysterectomies was reduced by half (from 81 to $39 \%$ ). Introduction of laparoscopic hysterectomy in 2007 allowed for further reduction of the abdominal resection rate (to $7.24 \%)$. Choice of a hysterectomy method alternative to abdominal resection was determined by hospitalization and recovery time, rates of intra- and postoperative complications, and patients' preferences especially in the aspect of preservation of the cervix and ligaments in supracervical hysterectomy and cosmetic effect.

Within 4 years in the gynaecological unit of the Tuchola Hospital abdominal hysterectomy was performed in $32.6 \%$ of patients, $\mathrm{VH}$ in $41.4 \%$ and $\mathrm{LH}$ in $26 \%$. In a report of the ACOG from 2009 these procedures were performed in the US respectively in $66 \%$, $22 \%$ and $12 \%$ of patients. In western Europe and Scandinavia the rate of vaginal hysterectomy is steadily growing (over 40\%). Most likely, this phenomenon originates from the influence of the German and French school. In Poland, the vaginal hysterectomy rate does not exceed $10 \%$, and laparoscopic hysterectomy is seldom performed, definitely not as a routine procedure.

Factors that affect the choice of access route for hysterectomy include the size and shape of the uterus and vagina, mobility of the uterus body, experience of the operator, available equipment and - more and more important today - the patient's opinion.

Nowadays, vaginal hysterectomy is considered the safest and least costly method of uterus resection for non-malignant diseases [3, 4]. However, when mobility of the uterus is limited, pathology of the adnexa is overt or intraperitoneal adhesions are present, laparoscopic hysterectomy - especially its supracervical modality - gains some significance. Shorter hospital stay of patients after LASH and perceptiveness of sexual problems result in a renaissance of this procedure, performed as one day surgery in some centres [11-13].

Progress in minimally invasive techniques shed some light on complications of the three types of hysterectomy. All reports show similar complication rates: the highest for abdominal, the smallest for vaginal hysterectomy [14-17]. Complications of laparoscopic hysterectomy include injuries to the urinary bladder, intestine and blood vessels and occur more often in total hysterectomy, mostly during the learning curve period and when advanced endometriosis or intraperitoneal adhesions are present [18-21]. In the material presented above, we have noted two cases of major complications $[22,23]$ due to the thermal injury to the ureter from the so-called delayed electric current effect [24-28], one diagnosed on the $14^{\text {th }}$ postoperative day as a uretero-vaginal fistula and the other on the $21^{\text {st }}$ day as leak of urine into the peritoneal cavity from the necrotic ureter. Both complications were successfully treated with surgery (end-to-end anastomosis and neoureterocystostomy). Complications occurred after LTH and LASH procedures done for myomas of the uterus and extensive adnexal endometriosis, in the first year from implementation of the LH procedure.

\section{Conclusions}

1. The training programme provided to physicians from the gynaecology unit of the Tuchola Hospital allowed for a halving of the rate of abdominal hysterectomies within one year, from 81.35 to $39.29 \%$, and a ten-fold reduction within 2 years (down to $7.24 \%)$.

2. Appropriate training and patient qualification allow the rate of vaginal hysterectomies to be increased to $60 \%$.

3. During the learning curve of laparoscopic hysterectomies more often conversion to laparotomy and the possibility of damage of the ureter must be expected.

\section{References}

1. Klimczak K, Katulski J, Malinowski A, Dejewski C. Wybór drogi operacyjnego usunięcia macicy a szkolenie w zakresie technik operacyjnych pochwowo-laparoskopowych - doniesienie wstępne. Prz Menopauz 2007; 5: 272-5.

2. Malinowski A, Maciołek-Blewniewska G. Dlaczego histerektomia pochwowa? Gin Pol 2007; 78: 434-42.

3. Schindlbeck C, Klauser K, Dian D, et al. Comparison of total laparoscopic, vaginal and abdominal hysterectomy. Arch Gynecol Obstet 2008; 277: 331-7.

4. Malinowski A, Cieślak J, Maciołek-Blewniewska G. Wpływ szkolenia w hysterektomii pochwowej na wybór drogi usunięcia macicy. Gin Pol 2007; 78.

5. Garry R. Health economics of hysterectomy. Best Pract Res Clin Obstet Gynaecol 2005; 19: 451-65.

6. Lethaby AE, Ivanova V, Johnson NP. Total versus subtotal hysterectomy for benign gynecological conditions, Cochrane Database Sys Rev 2006; 2: CD004993.

7. Johnson N, Barlow D, Lethaby A, et al. Surgical approach to hysterectomy for benign gynecological disease. Cohrane Database Sys Rev 2006; CD003677. 
8. Malinowski A, Bobin L, Maciołek-Blewniewska G. Histerektomia przez pochwę wspomagana laparoskopowo i histerektomia brzuszna - porównanie metod. Przegl Gin Pol 2005; 5: 9-14.

9. Dian D, Rack B, Schindlbeck C, Janni W, et al. Endoskopische Hysterektomie, Gynaekologe 2008; 41: 343-8.

10. Johnson N, Barlow D, Lethaby A, et al. Methods of hysterectomy: systematic review and meta-analysis of randomized controlled trials. BMJ 2005; 330: 1478-81.

11. Altgassen C, Michels W, Schneider A, Diedrich K. Wie sicher ist die laparoskopisch assistierte vaginale Hysterektomie? Geburtsh Frauenheilk 2005; 65: 1051-7.

12. Silva-Filho AL, Werneck RA, De Magalhaes RS, et al. Abdominal versus vaginal hysterectomy: a comparative study of the postoperative quality of life and satisfaction. Arch Gynecol Obstet 2006; 274: 21-4.

13. Sheth SS. The scope of vaginal hysterectomy. Eur J Obstet Gynecol Reprod Biol 2004; 115: 224-30.

14. Jacobson GF, Shaber RE, Armstrong MA, Hung Y. Hysterectomy rates for benign indications. Obstet Gynecol 2006; 107: 1278-83.

15. Whiteman MK, Hillis SD, Jamieson DJ, et al. Inpatient hysterectomy surveillance in the United States, 2000-2004. Am J Obstet Gynecol 2008; 198: 34.e1-7.

16. Tsaltas J, Healy DL, Lloyd D. Review of major complications of laparoskopy in a free-standing gynaecological day case hospital. Gynaecol Endosc 1996; 771-854.

17. Querleu D, Chevallier L, Chapron C, et al. Complications of gynaecological laparoscopic burgery. A French multicentre collaborative study. Gynaecol Endosc 1993; 2: 3-6.

18. Phipps JH. Avoidance of complications of laparoscopic hysterectomy. Baill Clin Obstet Gynecol 1995; 9: 729-48.

19. Mirhashemi R, Harlow BL, Ginsburg ES, et al. Predicting risk of complications with gynecologic laparoscopic surgery. Obstet Gynecol 1998; 92: 327-31.

20. Liu CY, Reich H. Complications of total laparoscopic hysterectomy in 518 cases. Gynaecol Endosc 1994; 3: 203-8.

21. Meikle SF, Nugent EW, Orleans M. Complications and recovery from laparoscopy-assisted vaginal hysterectomy compared with abdominal and vaginal hysterectomy. Obstet Gynecol 1997; 89: 304-11

22. Makinen J, Johansson J, Tomas C, et al. Morbidity of 10110 hysterectomies by type of approach. Hum Reprod 2001; 16 1473-8.

23. Li TC, Saravelos H, Richmond M, Cooke ID. Complications of laparoscopic pelvic surgery: recognition, management and prevention. Hum Reprod 1997; 3: 505-15.

24. Hornemann A, Thill M, Bohlmann MK, et al. Hysterektomie vaginal, abdominal oder laparoskopisch assistiert? Gynaekologe 2008; 41: 337-42.

25. Grainger DA, Soderstrom RM, Schiff SF, et al. Ureteral injuries at laparoscopy: insights into diagnosis, management and prevention. Obstet Gynecol 1990; 75: 839-43.

26. Lehmann-Willenbrock E, Riedel HH, Mecke H, Semm K. Pelviscopy/laparoscopy and its complications in Germany 1949-1988. J Reprod Med 1992; 37: 671-7.

27. Saidi MH, Sadler RK, Vancaillie TG, et al. Diagnosis and management of serious urinary complications after major operative laparoscopy. Obstet Gynecol 1996; 87: 272-6.
28. Tamussino KF, Lang PFJ, Breinl E. Ureteral complications with operative gynecologic laparoscopy. Am J Obstet Gynecol 1998; 178: 976-0. 